\title{
Exfoliated graphite nanoplatelet-filled impact modified polypropylene nanocomposites: influence of particle diameter, filler loading, and coupling agent on the mechanical properties
}

\author{
Alex J. Duguay $\cdot$ Jacques W. Nader • \\ Alper Kiziltas • Douglas J. Gardner • \\ Habib J. Dagher
}

Received: 8 October 2012/Accepted: 12 February 2013/Published online: 5 March 2013

(C) The Author(s) 2013. This article is published with open access at Springerlink.com

\begin{abstract}
Exfoliated graphite nanoplatelets (xGnP)-filled impact-modified polypropylene (IMPP) composites were prepared at 2, 4, 6, and $8 \mathrm{wt} \% \mathrm{xGnP}$ with and without the addition of a coupling agent and manufactured using melt mixing followed by injection molding. The coupling agent used in this study was polypropylene-graft-maleic anhydride (PP-g-MA). The nanoparticles used were $\mathrm{xGnP}$ with three different sizes: $\mathrm{xGnP}^{5}$ has an average thickness of $10 \mathrm{~nm}$, and an average platelet diameter of $5 \mu \mathrm{m}$, whereas $\mathrm{xGnP}^{15}$ and $\mathrm{xGnP}^{25}$ have the same thickness but average diameters are 15 and $25 \mu \mathrm{m}$, respectively. Test results show that nanocomposites with smaller $\mathrm{xGnP}$ diameter exhibited better flexural and tensile properties for both neat and compatibilized composites. For composites containing a coupling agent, tensile and flexural modulus and strength increased with the addition of $x \mathrm{GnP}$. In the case of neat composites, both tensile and flexural modulus and strength decreased at higher filler loading levels. Increasing $\mathrm{xGnP}$ loading resulted in reduction of elongation at break for both neat and composites containing coupling agent. Explanation of this brittle behavior in a nanoplatelet-filled IMPP is presented using scanning electron microscopy and transmission electron microscopy.
\end{abstract}

\section{A. J. Duguay · J. W. Nader · A. Kiziltas ·}

D. J. Gardner · H. J. Dagher

Advanced Structures and Composites Center (AEWC) Center, University of Maine, Orono, ME 04469, USA

e-mail: alex.duguay@umit.maine.edu

\section{A. Kiziltas $(\bowtie)$}

Department of Forest Industry Engineering, Faculty of Forestry, University of Bartin, 74100 Bartin, Turkey

e-mail: alper.kiziltas@umit.maine.edu
Keywords Graphite $\cdot$ Nanoplatelets · Polypropylene · Nanocomposite $\cdot$ Coupling agent $\cdot$ Morphology

\section{Introduction}

Polymer nanocomposites (PNCs) are continuing to be of great interest in the thermoplastics industry. Nano-reinforcing fillers can be divided into three categories based on particle morphologies as illustrated in Fig. 1. The first category is made up of spherical particles exhibiting three dimensions on the nanoscale. A few examples of these are gold, titanium oxide, and silica dioxide particles. The second category consists of rods, tubes, and whiskers having two dimensions on the nanoscale. Some examples of these are gold and silver nano rods, multi-wall and single-wall carbon nanotubes, and cellulose nanowhiskers. Finally, the third category contains layered structural fillers exhibiting one dimension on the nanoscale. Typical fillers from this category used for mechanical enhancement are exfoliated graphite nanoplatelets, mica, and nanoclays (Kim et al. 2010a, b, c). Incorporating nanoscale fillers into polymer matrices can be a simple and economical process to enhance the properties of the neat matrix material (Ahmad et al. 2007). In fact, dramatic improvements in mechanical and thermal properties have been documented with as little as 2-6 weight percentage of nanoparticles introduced into thermoplastic matrices via melt compounding. Currently, the most commonly used nano reinforcement phase is layered silicate nanoclays and carbon nanotubes (CNTs) (Lilli Manolis.et al. 2004).

Recently, there has been increasing interest in the use of exfoliated graphite nanoplatelets $(\mathrm{xGnP})$ as a multifunctional reinforcement phase for PNCs. These graphitic nanoplatelets, derived from expanded graphite (EG), 
Fig. 1 Three categories of nano-reinforcing fillers based on particle geometry

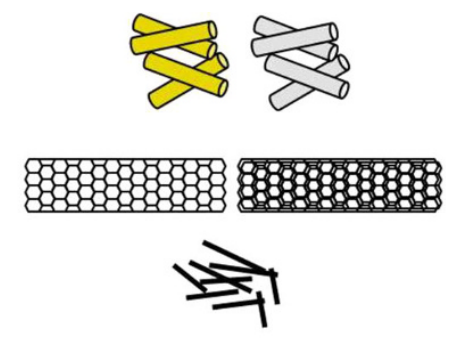

Rods, Tubes and Whiskers

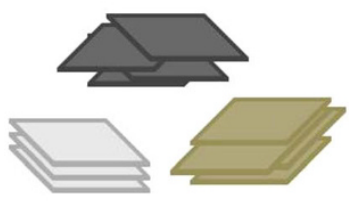

Layered Structures
Spherical

combine the low-cost and stacked or layered structures of nanoclays with a unique plethora of properties usually exhibited by CNTs including electrical conductivity, and superior mechanical, physical, and thermal properties (Pan et al. 2000; Kim et al. 2010a, b, c; Kalaitzidou et al. 2007a, b, c, d; Stankovich et al. 2006; Kim and Drzal 2009; Kim et al. 2009; Chen et al. 2001; Park et al. 2007; Miloaga et al. 2005; Jiang and Drzal 2010). Unfortunately, similar to nanoclay dispersions, in the absence of a coupling agent the stacks of nano-thin graphite sheets do not readily exfoliate when incorporated into thermoplastic matrices. Rather than exfoliating into individual graphene sheet reinforcements, the stacks of $\mathrm{xGnP}$ tend to remain agglomerated, exhibiting an intercalated dispersion (Ratnayake et al. 2009).

Polypropylene (PP) is among the most commonly used thermoplastics in the world with a vast range of applications in the automobile and construction industries (Teng et al. 2008). PP is non polar and does not interact with chemically inert graphite. Therefore, producing graphitereinforced PP nanocomposites is very difficult because of the lack of affinity between the two constituents. This issue can be overcome by adding a coupling agent such as polypropylene-graft-maleic anhydride (PP-g-MA) (Gopakumar and Page 2004; Spoljaric et al. 2009). According to a study by Page et al. (2006), XRD and SEM results indicate that the functionalization of PP by addition of PPg-MA leads to an excellent dispersion of graphite, and improvement in flexural properties of the material.

The objective of this study was to investigate the influence of particle diameter, filler loading, and coupling agent on the flexural and tensile mechanical properties of $\mathrm{xGnP}$-filled IMPP composites. The ultimate goal is to enhance the stiffness, strength and overall toughness of IMPP using $\mathrm{xGnP}$. All compounded materials were manufactured using melt mixing followed by injection molding and were prepared at 2, 4, 6, and $8 \mathrm{wt} \% \mathrm{xGnP}$. The weight ratio of filler-to-coupling agent was held constant at 2:1 throughout this study. Mechanical characterization was accomplished via flexural and tensile tests. Morphological characterization was conducted by means of scanning electron microscopy (SEM) and transmission electron microscopy (TEM). This research paper will be followed by two more publications related to the thermal properties (part II) and melt rheological behavior (part III) of the xGnP-filled IMPP composites.

\section{Experimental}

\section{Materials}

The IMPP was supplied as polymer pellets by Polystrand Inc., USA. The IMPP had a density of $0.900 \mathrm{~g} / \mathrm{cm}^{3}$ and melt flow index of $35 \mathrm{~g} / 10 \mathrm{~min}$. The $\mathrm{xGnP}$ fillers were supplied by XG Sciences Inc., USA. Three $\mathrm{xGnP}$ fillers in powder form were used as the reinforcement with different particle diameters 5, 15, and $25 \mu \mathrm{m}$. Average platelet thickness ranges from about 5 to $15 \mathrm{~nm}$. This translates into an average particle surface area ranging from about 60 to $150 \mathrm{~m}^{2} / \mathrm{g}$. The bulk density of all three $\mathrm{xGnP}$ fillers is reported to be $0.18-0.25 \mathrm{~g} / \mathrm{cm}^{3}$. Two different PP-g-MA were used as coupling agents, labeled for this study as SA9100 and WL9100, provided by Sigma-Aldrich Co., USA and West Lake Chemical Co., USA, respectively. Both coupling agents had a density of $0.934 \mathrm{~g} / \mathrm{cm}^{3}$, molecular weight of 9,100 by GPC, and acid number of 45-47. SA9100 and WL9100 coupling agents differed in that their maleic anhydride content was $8-10$ and $<0.7 \%$, respectively. Materials used in this study are summarized in Table 1.

Processing of composite materials

The matrix polymer IMPP was mixed with the $\mathrm{xGnP}$ fillers. The compounding was carried out with a Brabender Prepmixer ${ }^{\circledR}$ equipped with a mixing bowl. The basic processing parameters used in this study are summarized in Table 2. The temperature was set to $180{ }^{\circ} \mathrm{C}$ and mixing speed was set at $60 \mathrm{rpm}$. All composite formulations were prepared in $150 \mathrm{~g}$ batches and all constituents were added to the mixer simultaneously. Mixing was done for $20 \mathrm{~min}$; this was an optimum processing time as determined from preliminary experiments. All composite compounds were then granulated using a lab scale grinder. The ground particles were 
Table 1 Summary of materials used in current study

\begin{tabular}{|c|c|c|c|c|c|}
\hline Material/supplier & Label & Density $\left(\mathrm{g} / \mathrm{cm}^{3}\right)$ & MA content $(\%)$ & $\mathrm{M}_{\mathrm{w}}$ & Acid \# \\
\hline Impact Modified Polypropylene/Polystrand Inc. & IMPP & 0.900 & - & - & - \\
\hline Exfoliate Graphite Nanoplatelets $5 \mu / \mathrm{XG}$ Sciences Inc. & $\mathrm{xGnP} \mathrm{P}^{5}$ & 2 & - & - & - \\
\hline Exfoliate Graphite Nanoplatelets $15 \mu / \mathrm{XG}$ Sciences Inc. & $\mathrm{xGnP}^{15}$ & 2 & - & - & - \\
\hline Exfoliate Graphite Nanoplatelets $25 \mu / \mathrm{XG}$ Sciences Inc. & $\mathrm{xGnP} \mathrm{P}^{25}$ & 2 & - & - & - \\
\hline Polypropylene-g-Maleic Anhydride/Sigma-Aldrich Co. & SA9100 & 0.934 & $8-10$ & 9,100 & 47 \\
\hline Polypropylene-g-Maleic Anhydride/West Lake Chemical Co. & WL9100 & 0.934 & $<0.7$ & 9,100 & 45 \\
\hline
\end{tabular}

Table 2 Basic operating parameters of the Brabender rheomixer

\begin{tabular}{llll}
\hline Batch size $(\mathrm{g})$ & Temperature $\left({ }^{\circ} \mathrm{C}\right)$ & RPM & Compounding time (min)
\end{tabular}

\begin{tabular}{llll}
\hline 150 & 180 & 60 & 20
\end{tabular}

then injection molded into ASTM test samples using a barrel temperature of $246{ }^{\circ} \mathrm{C}$ and injection pressure of 2,500 psi. The designated labels and compositions of all compounded materials with and without the addition of a coupling agent are shown in Tables 3 and 4, respectively.

\section{Mechanical characterization}

Tensile tests were conducted according to the American Society of Testing and Materials (ASTM) standard D 638-03, "Standard Test Method for Tensile Properties of Plastics". The tensile behaviors of composites were measured using an Instron 8801 with a $5 \mathrm{kN}$ load cell. All the tensile tests were conducted at a rate of $5.08 \mathrm{~mm} / \mathrm{min}$. An extensometer was used for elongation determinations. Tensile modulus of the polymer composites was determined from the slope of the linear portion of the stressstrain curve. Tensile strength was calculated from the maximum load of the load-displacement curve divided by the sample original cross-sectional area. Elongation at break was also reported. At least five samples were tested for each composition and the results are presented as an average for tested samples.

Flexural tests were conducted according to ASTM D 790-07, "Standard Test Methods for Flexural Properties of Unreinforced and Reinforced Plastics and Electrical Insulating Materials", Procedure A. This test consisted of a three-point loading system introducing mid-span loading using an Instron 8801 with a $225 \mathrm{~N}$ load cell. The support span was $52.8 \mathrm{~mm}$, resulting in a span-to-depth ratio of 16 $( \pm 1)$. All flexural tests were conducted at a rate of $1.27 \mathrm{~mm} / \mathrm{min}$. Flexural modulus of the polymer composites was determined using Eq. 1 and inputting the slope of the linear portion of the load-deflection curve for the variable $m$. Flexural strength was calculated using Eq. 2 and inputting the maximum load of the load-displacement curve for the variable $P$. The other variables in the equation are $L, b$, and $d$, which is the span, width and depth of the beam specimen, respectively. At least five samples were tested for each composition and the results are presented as an average for tested samples.

$E_{\mathrm{b}}=\frac{L^{3} m}{4 b d^{3}}$
Table 3 Designated labels and compositions of $\mathrm{xGnP}$-filled neat composites

\begin{tabular}{|c|c|c|c|c|c|c|}
\hline \multirow[t]{2}{*}{ Study label } & \multicolumn{6}{|c|}{ Content per batch $(\mathrm{g})$} \\
\hline & IMPP & SA9100 & WL9100 & $\mathrm{xGnP}^{5}$ & $x \mathrm{GnP}^{15}$ & $\mathrm{xGnP}^{25}$ \\
\hline IMPP_xGnP ${ }^{5} \_2 \%$ & 147 & - & - & 3 & - & - \\
\hline IMPP_xGnP ${ }^{5} \_4 \%$ & 144 & - & - & 6 & - & - \\
\hline IMPP_xGnP ${ }^{5} \_6 \%$ & 141 & - & - & 9 & - & - \\
\hline IMPP_xGnP 5 _8 \% & 138 & - & - & 12 & - & - \\
\hline IMPP_xGnP ${ }^{15} \_2 \%$ & 147 & - & - & - & 3 & - \\
\hline IMPP_xGnP ${ }^{15} \_4 \%$ & 144 & - & - & - & 6 & - \\
\hline IMPP_xGnP ${ }^{15} \_6 \%$ & 141 & - & - & - & 9 & - \\
\hline IMPP_xGnP ${ }^{15} \_8 \%$ & 138 & - & - & - & 12 & - \\
\hline IMPP_xGnP ${ }^{25} \_2 \%$ & 147 & - & - & - & - & 3 \\
\hline IMPP_xGnP ${ }^{25} \_4 \%$ & 144 & - & - & - & - & 6 \\
\hline IMPP_xGnP ${ }^{25} \_6 \%$ & 141 & - & - & - & - & 9 \\
\hline IMPP_xGnP ${ }^{25} \_8 \%$ & 138 & - & - & - & - & 12 \\
\hline
\end{tabular}


Table 4 Designated labels and compositions of $\mathrm{xGnP}$-filled composites with the addition of coupling agents $\sigma_{\mathrm{f}}=\frac{3 P L}{2 b d^{2}}$

Morphological characterization

Studies regarding the microscopic morphology of the tensile fracture surfaces of the composites were carried out using an AMR 1000 (AMRay Co.) scanning electron microscope. Images were taken at $10 \mathrm{kV}$ with $1,200 \times$, $6,200 \times$ and $13,000 \times$ SEM micrograph magnifications. All samples were sputter coated with gold before the microscopic observations were obtained. The nanoscale morphology of the PNCs was completed using a Phillips CM10 transmission electron microscope. Images were taken at magnifications of $130 \mathrm{k} \times, 245 \mathrm{k} \times$ and $450 \mathrm{k} \times$. Sectioning of thermoplastics is a difficult task because of their inherently soft characteristics. In the absence of low temperature ultra-cryotome technology, a method for obtaining ultrathin sections was necessary. Thin slivers of our composites were shaved and embedded in an epoxy matrix to aid in sectioning the soft plastic. The embedded sample was then sectioned using a Leica EM UC6 ultra-microtome equipped with a diamond knife. Samples were sectioned with thickness on the order of 50-75 $\mathrm{nm}$.

\begin{tabular}{llllll}
\multicolumn{7}{l}{ Content per batch $(\mathrm{g})$} & & & & \\
\hline IMPP & SA9100 & WL9100 & $\mathrm{xGnP}^{5}$ & $\mathrm{xGnP}^{15}$ & $\mathrm{xGnP}^{25}$ \\
\hline 145.5 & 1.5 & - & 3 & - & - \\
141 & 3 & - & 6 & - & - \\
136.5 & 4.5 & - & 9 & - & - \\
132 & 6 & - & 12 & - & - \\
145.5 & 1.5 & - & - & 3 & - \\
141 & 3 & - & - & 6 & - \\
136.5 & 4.5 & - & - & 9 & - \\
132 & 6 & - & - & 12 & - \\
145.5 & 1.5 & - & - & - & 3 \\
141 & 3 & - & - & - & 6 \\
136.5 & 4.5 & - & - & - & 9 \\
132 & 6 & - & - & - & 12 \\
145.5 & - & 1.5 & 3 & - & - \\
141 & - & 3 & 6 & - & - \\
136.5 & - & 4.5 & 9 & - & - \\
132 & - & 6 & 12 & - & - \\
145.5 & - & 1.5 & - & 3 & - \\
141 & - & 3 & - & 6 & - \\
136.5 & - & 4.5 & - & 9 & - \\
132 & - & 6 & - & 12 & - \\
145.5 & - & 1.5 & - & - & 3 \\
141 & - & 3 & - & - & 6 \\
136.5 & - & 4.5 & - & - & 9 \\
132 & - & 6 & - & - & 12 \\
\hline & & & & &
\end{tabular}

Statistical analysis

The flexural modulus, flexural strength, tensile modulus, tensile strength, and elongation at break were compared using a one-way analysis of variance followed by TukeyKramer Honestly Significant Differences (HSD) test at a confidence value equal to 0.05 with JMP statistical analysis program (JMP 9) (JMP Statistical Discovery Software, Version 8 SAS Institute, Inc.: Cary, NC 2008).

\section{Results and discussions}

Flexural properties

Neat IMPP was determined to have flexural modulus and flexural strength equal to 1.1 and $33.7 \mathrm{MPa}$, respectively. Normalized flexural modulus results for neat and $\mathrm{xGnP}^{5}$ filled composites with coupling agent as a function of filler loading level up to $8 \%$ are presented in Fig. 2. Similar plots are provided for neat and $\mathrm{xGnP}^{15}$ - and $\mathrm{xGnP}^{25}$-filled composites with coupling agent in Figs. 3 and 4, respectively. In general, flexural modulus was found to increase 


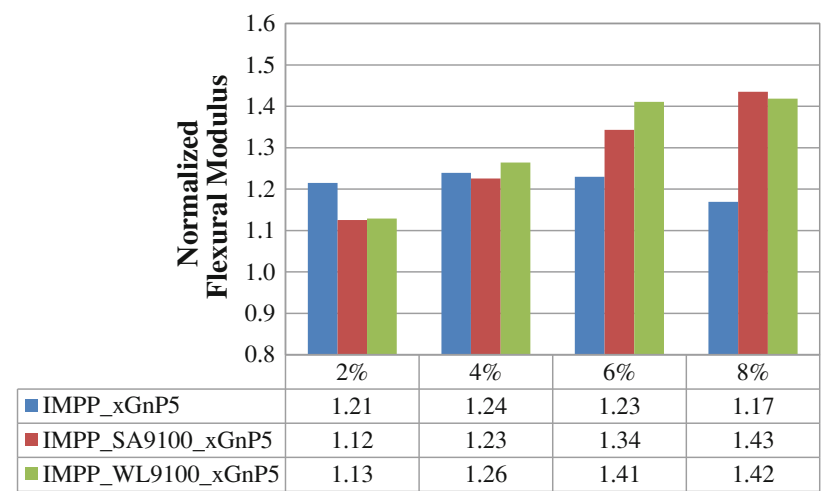

Fig. 2 Normalized flexural modulus experimental results for $\mathrm{xGnP}^{5}$ filled composites

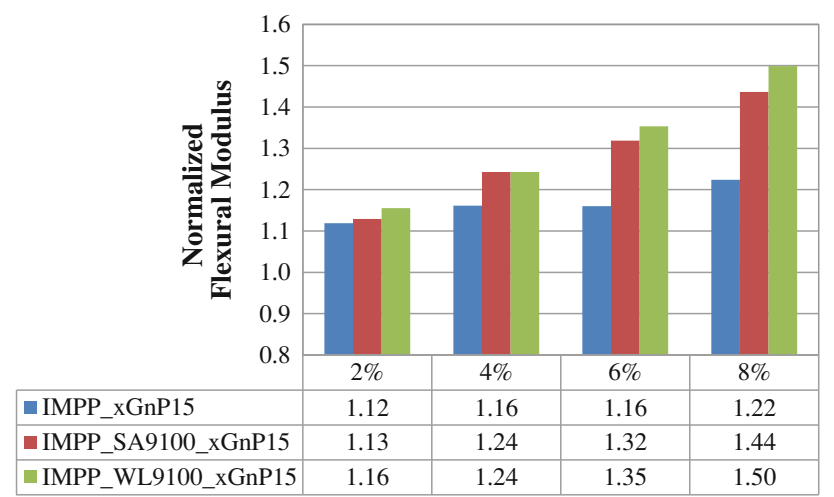

Fig. 3 Normalized flexural modulus experimental results for $\mathrm{xGnP}^{15}$-filled composites

with decreasing $\mathrm{xGnP}$ particle diameter and increased filler loading for both neat and xGnP-filled composites containing coupling agent. However, flexural modulus increased with filler loading much more efficiently at higher loading levels for composites containing coupling agent. In general, the optimum formulation to improve flexural modulus for filler loading levels 2, 4, 6, and $8 \mathrm{wt} \%$ is IMPP_WL9100_xGnP ${ }^{15}$ composites. The resulting improvement from neat IMPP is $16,24,35$, and $50 \%$, respectively.

Normalized flexural strength results for neat and $\mathrm{xGnP}^{5}$ filled composites with coupling agent as a function of filler loading level up to $8 \%$ are presented in Fig. 5. Similar plots are provided for neat and $\mathrm{xGnP}^{15-}$ and $\mathrm{xGnP}^{25}$-filled composites with coupling agent in Figs. 6 and 7, respectively. Flexural strength was found to increase with decreasing $\mathrm{xGnP}$ particle diameter for all filler loading values of both neat and $\mathrm{xGnP}$-filled composites containing coupling agent. Flexural strength increases with filler loading for all $\mathrm{xGnP}$-filled composites containing coupling agent. However, flexural strength decreased with increased filler loading for neat composites. The optimum formulation

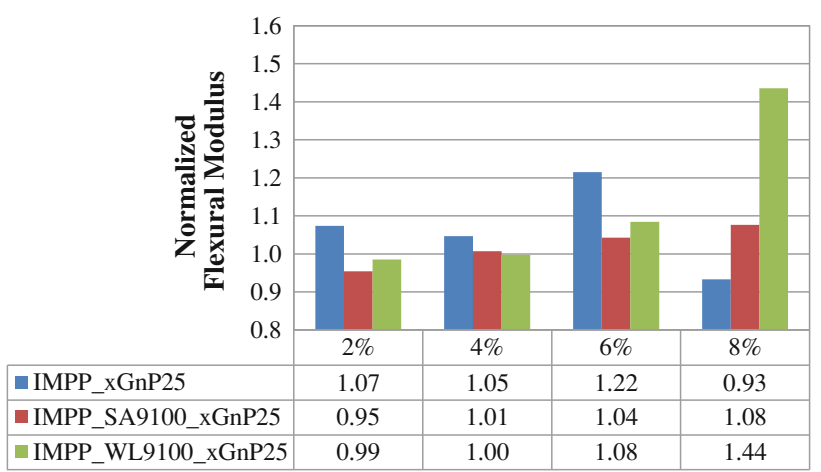

Fig. 4 Normalized flexural modulus experimental results for $\mathrm{xGnP}^{25}$-filled composites

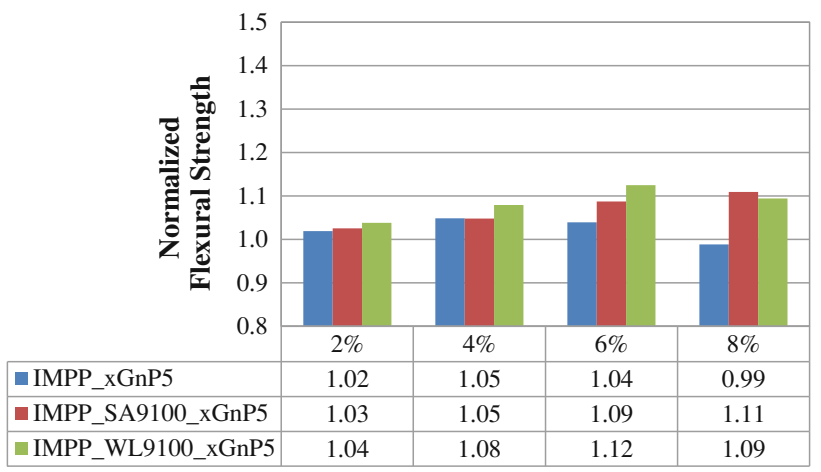

Fig. 5 Normalized flexural strength experimental results for $\mathrm{xGnP}^{5}$ filled composites

to improve flexural strength for filler loading levels $2,4,6$, and $8 \mathrm{wt} \%$ is IMPP_WL9100_xGnP ${ }^{5}$ composites. The resulting improvement from neat IMPP is 4, 8, 12, and $9 \%$, respectively.

Research performed by Kalaitzidou et al. (2007b, c) showed much greater improvement in flexural modulus compared to results shown here. Using $\mathrm{xGnP}^{1}$ in polypropylene homopolymer, they obtained flexural modulus improvement of $\sim 900 \%$ at a loading of $20 \mathrm{vol} . \%$ ( $~ 6$ wt $\%$ ). Such a large improvement may be attributed to the five-fold decrease in $\mathrm{xGnP}$ particle diameter. The importance of the dispersion of the reinforcing filler was also a highlight of this article. Kalaitzidou (2007a, b, d) found that $\mathrm{xGnP}^{15}$ was susceptible to agglomeration and fiber buckling or rollup. On the contrary, when $\mathrm{xGnP}^{1}$ was incorporated into the polypropylene matrix, although some agglomerations were present, they appear in much smaller effective particle sizes. These findings are very similar to this study's morphological findings presented in next section.

This study proved feasibility of improving flexural modulus and strength of IMPP using $\mathrm{xGnP}$ as a nano reinforcement phase and PP-g-MA as a coupling agent. 


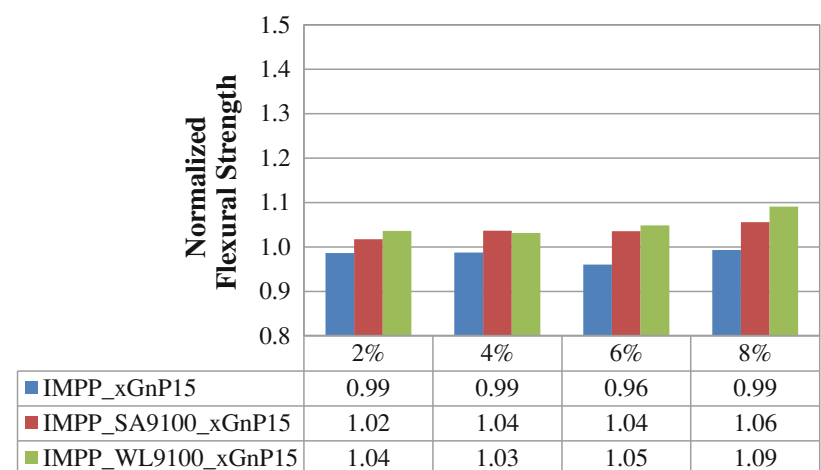

Fig. 6 Normalized flexural strength experimental results for $\mathrm{xGnP}^{15}$-filled composites

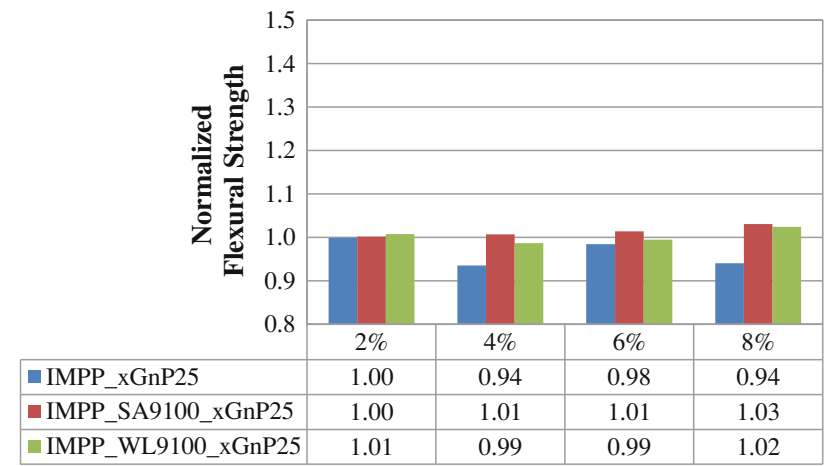

Fig. 7 Normalized flexural strength experimental results for $\mathrm{XGnP}^{25}$-filled composites

However, it is suspected that incorporation of $\mathrm{xGnP}$ with an average particle diameter smaller than $5 \mu \mathrm{m}$ would inevitably lead to largely increased improvements in flexural properties. Table 5 shows a summary of flexural mechanical properties and statistical significance of all compounded materials.

Tensile properties

Neat IMPP was determined to have tensile modulus, tensile strength and elongation at break equal to $1.29 \mathrm{GPa}$, 21.3 $\mathrm{MPa}$, and $33.8 \%$, respectively. Normalized tensile modulus results for neat and $\mathrm{xGnP}^{5}$-filled composites with coupling agent as a function of filler loading level up to $8 \%$ are presented in Fig. 8. Similar plots are provided for neat and $\mathrm{xGnP}^{15}$ - and $\mathrm{xGnP}^{25}$-filled composites with coupling agent in Figs. 9 and 10, respectively. Tensile modulus was found to increase with decreasing $\mathrm{xGnP}$ particle diameter for all filler loading values of both neat and xGnP-filled composites containing coupling agent. Tensile modulus remains statistically unchanged with increased filler loading for neat xGnP-filled composites. However, tensile modulus consistently increases with increased filler loading for all SA9100 and WL9100 coupled $x$ GnP filled composites. In general, the
Table 5 Summary of flexural mechanical properties and statistical significance (Tukey-Kramer HSD comparison at $\alpha=0.05$ ) of all compounded materials

\begin{tabular}{|c|c|c|c|c|}
\hline \multirow[t]{2}{*}{ Study label } & \multicolumn{4}{|c|}{ Flexural properties } \\
\hline & $\begin{array}{l}\text { Modul } \\
(\mathrm{GPa})\end{array}$ & & $\begin{array}{l}\text { Strength } \\
(\mathrm{MPa})\end{array}$ & \\
\hline Neat IMPP & LMN & $1.08(0.06)$ & JKLMNO & $33.7(1.0)$ \\
\hline IMPP_xGnP ${ }^{5} \_2 \%$ & FGH & $1.31(0.04)$ & GHIJKL & $34.3(1.4)$ \\
\hline IMPP_xGnP ${ }^{5}{ }^{4} \%$ & $\mathrm{~F}$ & $1.33(0.03)$ & $\mathrm{EF}$ & $35.3(0.7)$ \\
\hline IMPP_xGnP ${ }^{5} \_6 \%$ & $\mathrm{~F}$ & $1.32(0.04)$ & EFG & $35.0(0.5)$ \\
\hline IMPP_xGnP ${ }^{5} \_\%$ & GHI & $1.26(0.02)$ & MNO & $33.3(0.4)$ \\
\hline IMPP_SA9100_xGnP ${ }^{5} \_2 \%$ & $\mathrm{IJ}$ & $1.21(0.02)$ & FGHIJK & $34.6(0.5)$ \\
\hline IMPP_SA9100_xGnP ${ }^{5} \_\%$ & FG & $1.32(0.01)$ & EF & $35.3(0.3)$ \\
\hline IMPP_SA9100_xGnP 5 _6\% & $\mathrm{D}$ & $1.44(0.02)$ & $\mathrm{BC}$ & $36.6(0.2)$ \\
\hline IMPP_SA9100_xGnP 5 _8\% & $\mathrm{B}$ & $1.54(0.01)$ & $\mathrm{AB}$ & $37.4(0.3)$ \\
\hline IMPP_WL9100_xGnP ${ }^{5} \_2 \%$ & $\mathrm{IJ}$ & $1.21(0.02)$ & EFG & $35.0(0.3)$ \\
\hline IMPP_WL9100_xGnP ${ }^{5} 4$ \% & $\mathrm{EF}$ & $1.36(0.02)$ & $\mathrm{CD}$ & $36.4(0.5)$ \\
\hline IMPP_WL9100_xGnP $56 \%$ & $\mathrm{BC}$ & $1.52(0.02)$ & A & $37.9(0.4)$ \\
\hline IMPP_WL9100_xGnP ${ }^{5} \_8 \%$ & $\mathrm{~B}$ & $1.53(0.03)$ & $\mathrm{BC}$ & $36.9(0.8)$ \\
\hline IMPP_xGnP ${ }^{15} \_2 \%$ & IJ & $1.20(0.01)$ & NO & $33.2(0.3)$ \\
\hline IMPP_xGnP ${ }^{15} \_4 \%$ & $\mathrm{HI}$ & $1.25(0.01)$ & NO & $33.3(0.3)$ \\
\hline IMPP_xGnP ${ }^{15} \_6 \%$ & FG & $1.25(0.04)$ & LMNO & $32.4(0.6)$ \\
\hline IMPP_xGnP ${ }^{15} \_8 \%$ & FG & $1.32(0.02)$ & LMNO & $33.5(0.3)$ \\
\hline IMPP_SA9100_xGnP ${ }^{15} \_2 \%$ & $\mathrm{IJ}$ & $1.21(0.02)$ & GHIJKLM & $34.3(0.4)$ \\
\hline IMPP_SA9100_xGnP ${ }^{15} \_4 \%$ & $\mathrm{~F}$ & $1.34(0.02)$ & EFGH & $34.9(0.3)$ \\
\hline IMPP_SA9100_xGnP ${ }^{15} \_6 \%$ & $\mathrm{DE}$ & $1.42(0.01)$ & EFGHI & $34.9(0.2)$ \\
\hline IMPP_SA9100_xGnP ${ }^{15} \_8 \%$ & B & $1.55(0.04)$ & $\mathrm{DE}$ & $35.6(0.7)$ \\
\hline IMPP_WL9100_xGnP ${ }^{15} \_2 \%$ & I & $1.24(0.01)$ & EFGH & $34.9(0.2)$ \\
\hline IMPP_WL9100_xGnP ${ }^{15}{ }^{4} \%$ & $\mathrm{~F}$ & $1.34(0.01)$ & EFGHI & $34.8(0.2)$ \\
\hline IMPP_WL9100_xGnP ${ }^{15} \_6 \%$ & $\mathrm{CD}$ & $1.46(0.04)$ & $\mathrm{EF}$ & $35.3(0.6)$ \\
\hline IMPP_WL9100_xGnP ${ }^{15} \_8 \%$ & A & $1.61(0.03)$ & $\mathrm{BC}$ & $36.8(0.4)$ \\
\hline IMPP_xGnP ${ }^{25} \_2 \%$ & JK & $1.15(0.08)$ & KLMNO & $33.7(1.0)$ \\
\hline IMPP_xGnP ${ }^{25} \_4 \%$ & KL & $1.13(0.05)$ & $\mathrm{P}$ & $31.5(0.5)$ \\
\hline IMPP_xGnP ${ }^{25} \_6 \%$ & FGH & $1.31(0.02)$ & $\mathrm{O}$ & $33.2(0.5)$ \\
\hline IMPP_xGnP ${ }^{25} \_8 \%$ & $\mathrm{O}$ & $1.00(0.03)$ & $\mathrm{P}$ & $31.7(1.0)$ \\
\hline IMPP_SA9100_xGnP ${ }^{25} \_2 \%$ & NO & $1.03(0.01)$ & JKLMNO & $33.8(0.3)$ \\
\hline IMPP_SA9100_xGnP ${ }^{25} \_4 \%$ & LMN & $1.08(0.01)$ & IJKLMNO & $33.9(0.3)$ \\
\hline IMPP_SA9100_xGnP ${ }^{25} \_6 \%$ & KLM & $1.12(0.01)$ & GHIJKLMN & $34.2(0.4)$ \\
\hline IMPP_SA9100_xGnP ${ }^{25} \_8 \%$ & JK & $1.16(0.01)$ & EFGHIJ & $34.7(0.4)$ \\
\hline IMPP_WL9100_xGnP ${ }^{25}{ }^{2} 2 \%$ & MNO & $1.06(0.03)$ & HIJKLMNO & $34.0(0.9)$ \\
\hline IMPP_WL9100_xGnP ${ }^{25}-4 \%$ & LMN & $1.07(0.01)$ & NO & $33.3(0.4)$ \\
\hline IMPP_WL9100_xGnP ${ }^{25} \_6 \%$ & JK & $1.17(0.13)$ & LMNO & $33.5(0.8)$ \\
\hline IMPP_WL9100_xGnP ${ }^{25} \_8 \%$ & B & $1.54(0.04)$ & FGHIJK & $34.5(0.5)$ \\
\hline
\end{tabular}

Parenthesis indicates standard deviation

Presence of the same letter indicates no statistical difference

optimum formulation to improve tensile modulus for filler loading levels $2,4,6$, and $8 \mathrm{wt} \%$ is IMPP_WL9100_xGnP ${ }^{5}$ composites. The resulting improvement from neat IMPP is 6 , 18,24 , and $31 \%$, respectively.

Test results show that PP-g-MA is extremely beneficial to dispersion, particularly at higher filler loading levels. As 


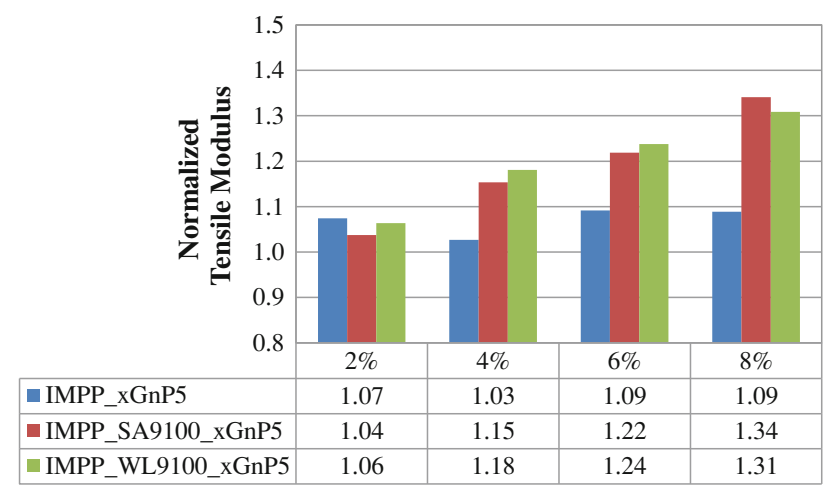

Fig. 8 Normalized tensile modulus experimental results for $\mathrm{xGnP}^{5}$ filled composites

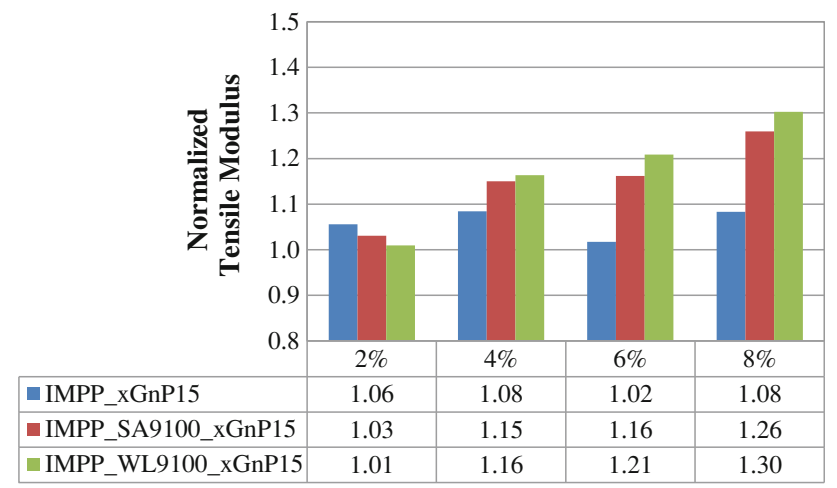

Fig. 9 Normalized tensile modulus experimental results for $\mathrm{xGnP}^{15}$ filled composites

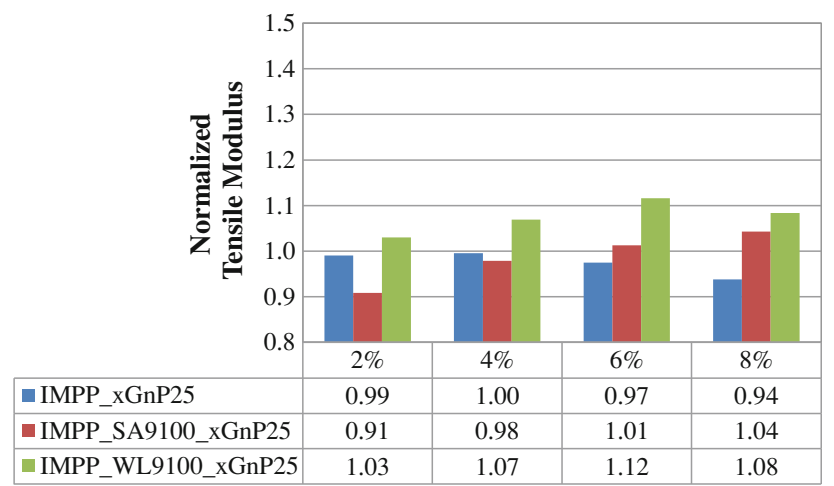

Fig. 10 Normalized tensile modulus experimental results for $\mathrm{xGnP}^{25}$-filled composites

discussed by Hussain et al. (2006) the degree of dispersion is one of the most critical aspects of layered nanomaterial reinforcement. In the absence of perfect exfoliation, the nano reinforcement phase will not provide improved mechanical properties. In fact, poorly dispersed nano fillers can greatly deteriorate the mechanical properties when compared to the neat polymer matrix. As described by Thostenson et al.
(2005), the individual graphene platelets have greater affinity to themselves compared to the polymer matrix. For this reason, perfect dispersion (exfoliation) of the nano particles is very difficult. Furthermore, it has been demonstrated that the magnitude of inherent stress concentrations decreases as the thickness at the tip of the graphite agglomerates decreases. Improvement in degree of exfoliation results in smaller thickness of graphite effective particles. Therefore, an improved degree of exfoliation results in lower stress concentrations and subsequently higher performance mechanical properties. TEM investigations are necessary to draw further conclusions regarding the influence of PP-gMA coupling agent on the degree of dispersion within our composites.

Transmission electron microscopy images are shown in Fig. 11 and illustrate the obvious improvement in quality of dispersion in properly compatibilized composites. In Fig. 11a, b, individual platelets can be seen and their individual thickness of $10 \mathrm{~nm}$ is confirmed. However, the individual platelets are present in stacks ranging from 50 to $200 \mathrm{~nm}$ in thickness. This nanoscale morphology is described as intercalated dispersion at best. Figure $11 \mathrm{c}, \mathrm{d}$ show with the addition of WL9100 coupling agent, individual platelets are visible at $10 \mathrm{~nm}$ thick, and polymer is also seen penetrating much of the gallery spacing among platelets resulting in stacks of only two or three platelets. This nanoscale morphology can be described as a partially exfoliated dispersion.

The Halpin-Tsai equation was introduced to predict the tensile longitudinal modulus of unidirectional fiber-reinforced composites. The Halpin-Tsai prediction of tensile modulus was calculated using Eq. 3 through Eq. 5 as shown:

$E=E_{m} \frac{1+\eta \xi V_{\mathrm{f}}}{1-\eta V_{\mathrm{f}}}$

$\eta=\frac{\frac{E_{f}}{E_{m}}-1}{\frac{E_{f}}{E_{m}}+\xi}$

$\xi=\frac{2}{3 a}$

where the parameter $E_{m}$ is the neat IMPP Young's modulus, $E_{f}$ is the elastic modulus of the fiber reinforcement phase, and $V_{\mathrm{f}}$ is the fiber volume fraction. The variable $\xi$ shown here is an adaptation for the case of platelet shaped fillers and is a function of the filler's aspect ratio, $a$. assumptions of the Halpin-Tsai equation include perfect exfoliation to attain the aspect ratio input into Eq. 5, as well as perfect contact between filler and matrix (Kalaitzidou et al. 2007b).

For the case of $\mathrm{xGnP}^{5}$, variables $E_{f}$ and $a$ were taken as $1 \mathrm{TPa}$ and 500, respectively. The predicted tensile modulus of various composites can then be plotted as a function of fiber volume fraction. Figures 12, 13 and 14 illustrate a comparison of Halpin-Tsai prediction of tensile modulus 
Fig. 11 Transmission electron micrographs of $(\mathbf{a}, \mathbf{b})$ IMPP_xGnP $52 \%$ and $(\mathbf{c}, \mathbf{d})$ IMPP_WL9100_xGnP ${ }^{5} \_\%$
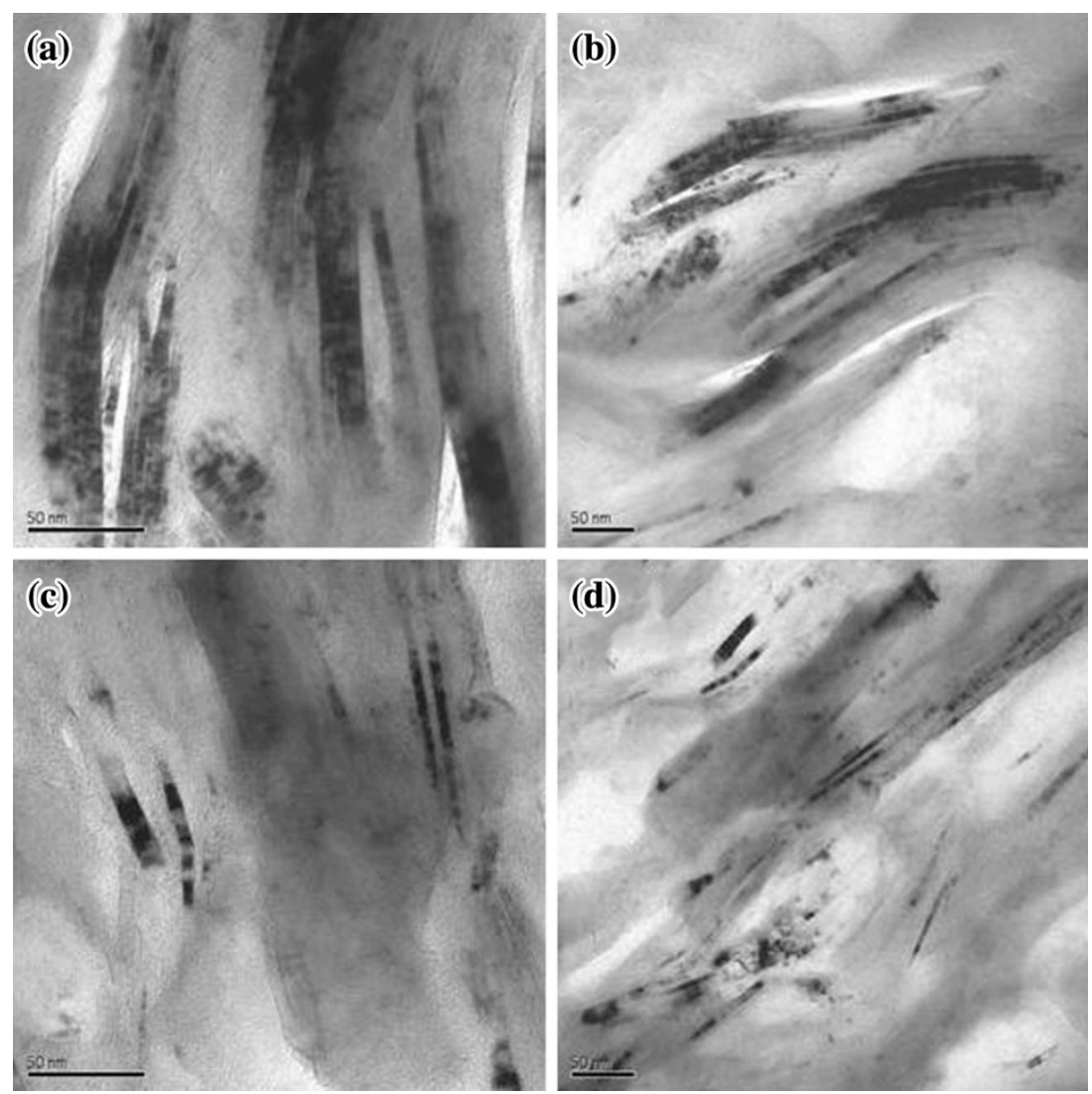

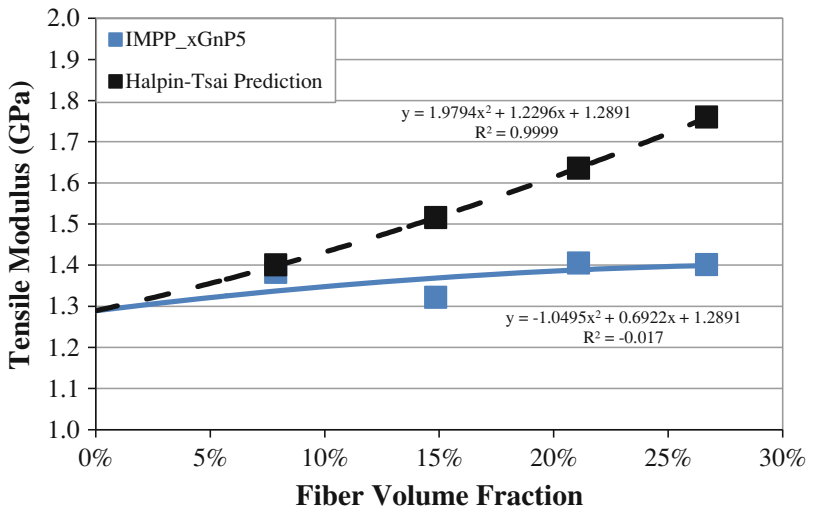

Fig. 12 Comparison of Halpin-Tsai prediction of tensile modulus with experimental results for neat $\mathrm{xGnP}^{5}$-filled composites

and experimental results fit to 2nd-order polynomials for neat and compatibilized $\mathrm{xGnP}^{5}$-filled composites. Figure 12 depicts a very poor agreement between the HalpinTsai prediction and experimental results for neat $\mathrm{xGnP}^{5}$ filled composites. On the contrary, both Figs. 13 and 14 show rather good agreement between the Halpin-Tsai prediction and experimental results for both SA9100 and WL9100 coupled $\mathrm{xGnP}^{5}$-filled composites. The 2 nd-order polynomial fit to the experimental data exhibited correlation coefficients, $R^{2}$, for composites containing coupling agent greater than 0.975. Coupled composites show

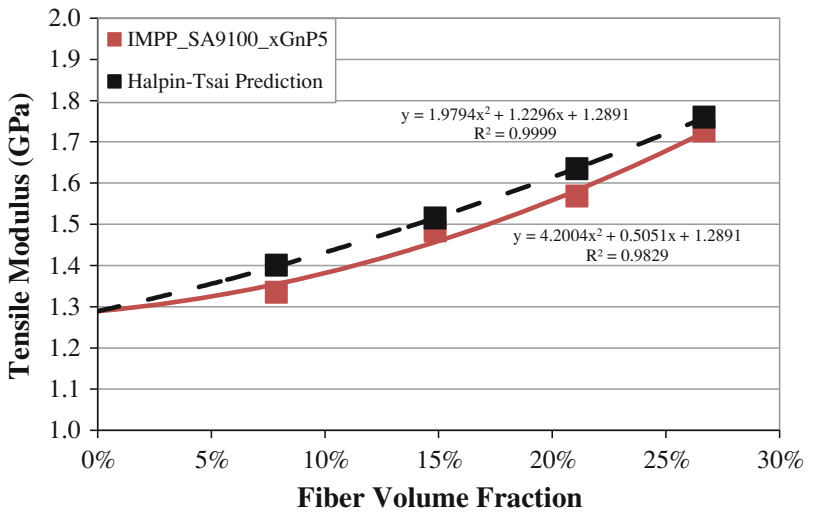

Fig. 13 Comparison of Halpin-Tsai prediction of tensile modulus with experimental results for SA9100 coupled $\mathrm{xGnP}^{5}$-filled composites

excellent agreement with the modeled prediction, particularly at higher filler loading levels when compared with neat composites.

The Halpin-Tsai model slightly over-predicts the composite tensile modulus. This is similar to other findings in the literature, where over-predictions of modulus using Halpin-Tsai equation are attributed to the theoretical aspect ratio that was input into the model. In actuality, agglomerations and distortion (e.g., buckling, folding, rollup) of the platelets during melt compounding can lead to 


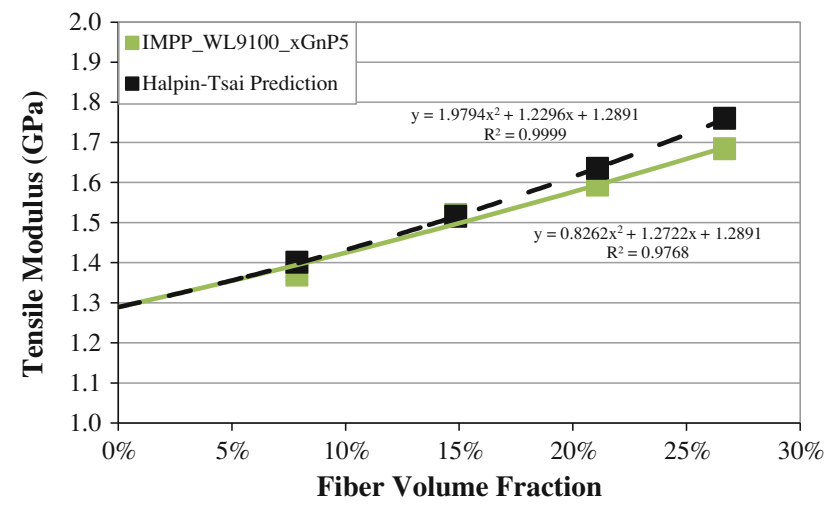

Fig. 14 Comparison of Halpin-Tsai prediction of tensile modulus with experimental results for WL9100 coupled $\mathrm{xGnP}^{5}$-filled composites

effective aspect ratios much smaller than calculated based on perfect exfoliation. Instead of perfectly exfoliated $10-\mathrm{nm}$ thick individual graphene sheets aligned in the injection mold flow direction, the effective particle thickness could be at least an order of magnitude larger and no longer in a planar geometric shape (Ahmad et al. 2007; Kalaitzidou et al. 2007a, b, c, d; Kim et al. 2010a, b, c). Evidence of this phenomenon occurring in this study is shown in Fig. 15 and is indicated by the red arrow. Analogous to slenderness in a structural column, the $\mathrm{xGnP}^{25}$ particle is relatively long and thin. Thus, the platelet is inherently susceptible to buckling, folding and roll-up during the intensive shear mixing induced during melt compounding. The other source of deviation from the Halpin-Tsai prediction is attributed to the assumption of perfect contact between the filler and the matrix.

Normalized tensile strength results for neat and $\mathrm{xGnP}^{5}$ filled composites with coupling agent as a function of filler loading level up to $8 \%$ are presented in Fig. 16. Similar plots are provided for neat and $\mathrm{xGnP}^{15}$ - and $\mathrm{xGnP}^{25}$-filled composites with coupling agent in Figs. 17 and 18, respectively. Tensile strength was found to increase with decreasing $\mathrm{xGnP}$ particle diameter for all filler loading values of both neat and xGnP-filled composites containing coupling agent. Tensile strength decreased with increased filler loading for all neat $\mathrm{xGnP}$-filled composites. However, tensile strength is statistically higher than neat IMPP at all filler loading level for WL9100 coupled $\mathrm{xGnP}^{5}$-filled composites. In general, the optimum formulation to improve tensile strength for filler loading levels $2,4,6$, and $8 \mathrm{wt} \%$ is IMPP_WL9100_xGnP ${ }^{5}$ composites. The resulting improvement from neat IMPP is $12,6,5$, and $5 \%$, respectively.

Normalized elongation at break results for neat and $\mathrm{xGnP}^{5}$-filled composites with coupling agent as a function of filler loading level up to $8 \%$ are presented in Fig. 19. Similar plots are provided for neat and $\mathrm{xGnP}^{15}$ - and $\mathrm{xGnP}^{25}$-filled composites with coupling agent in Figs. 20 and 21, respectively. In general, elongation at break increased with decreasing $\mathrm{xGnP}$ particle diameter for all filler loading values of both neat and $\mathrm{xGnP}$-filled composites containing coupling agent. However, elongation at break decreased with increased filler loading for all neat and $\mathrm{xGnP}$-filled composites containing coupling agent. It is important to note that the addition of coupling agent caused lower elongation at break and therefore a more brittle behaving composite. The optimum formulation to obtain the least degradation of elongation at break for filler loading levels $2,4,6$, and $8 \mathrm{wt} \%$ is IMPP_xGnP ${ }^{5}$ composites. The resulting degradation when compared to neat IMPP is $13,29,44$, and $41 \%$, respectively.

According to Ahmad et al. (2007), nearly any filled polymer will show an increase in modulus and strength while concurrently producing a more brittle behaving composite. The $\mathrm{xGnP}$ is an extremely rigid particle. Therefore, nearly all elongation of the specimen during the

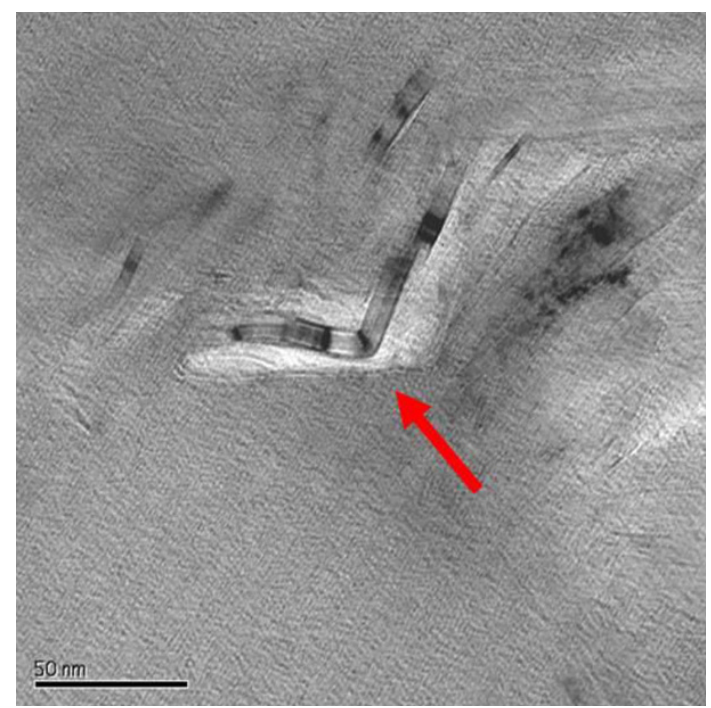

Fig. 15 Transmission electron micrograph of IMPP_SA9100_ $\mathrm{xGnP}^{25} \_4 \%$ showing evidence of platelet buckling

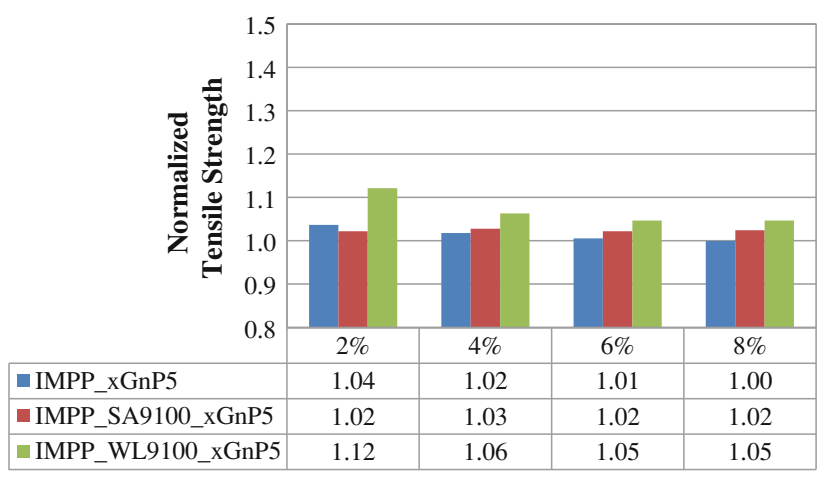

Fig. 16 Normalized tensile strength experimental results for $\mathrm{xGnP}^{5}$ filled composites 


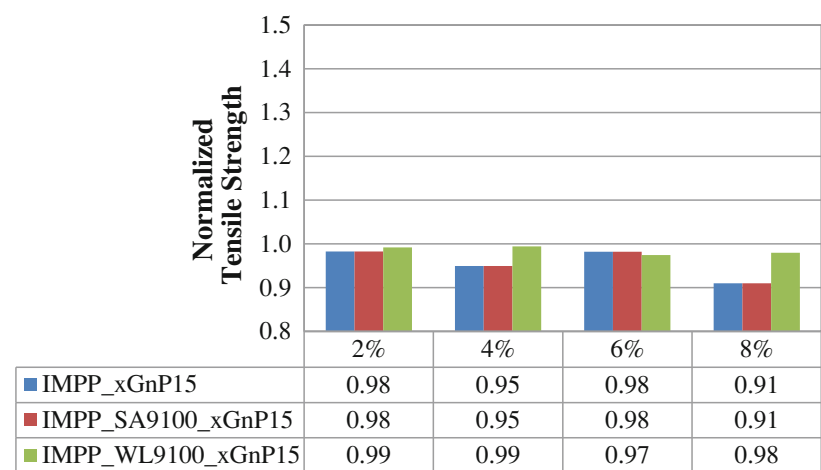

Fig. 17 Normalized tensile strength experimental results for $\mathrm{xGnP}^{15}$ filled composites

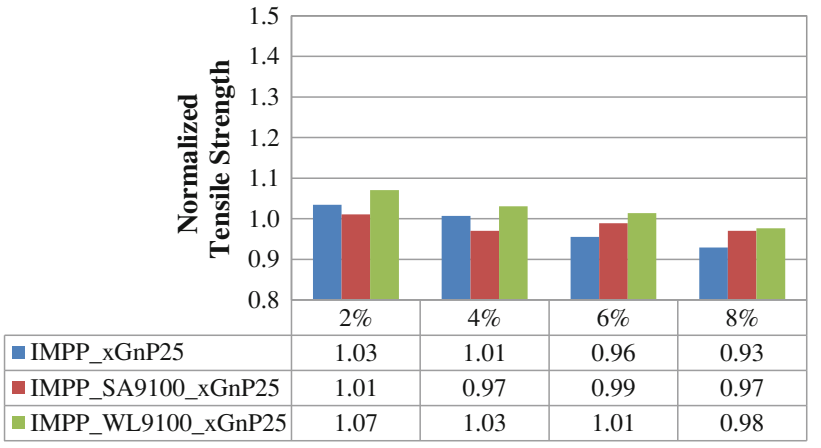

Fig. 18 Normalized tensile strength experimental results for $\mathrm{xGnP}^{25}$ filled composites

tensile test will occur in the matrix. When there is good adhesion between the filler and the matrix, a significant decrease in elongation at break can be expected even at small filler loading levels. In the case of poor adhesion, the decrease in elongation at break is expected to be more gradual (Oksman and Clemons 1998). This study's composites containing coupling agent have been proven to exhibit improved dispersion and are expected to exhibit improved adhesion at the particle/matrix interface as proposed in the previously discussed Halpin-Tsai comparison plots. Poor particle/matrix adhesion can be seen in SEM images of tensile fracture surfaces where no polymer is found to be attached to or coating embedded fillers. This phenomenon is seen here as shown in Fig. 22 and is indicated by the red arrow where the tensile fracture surface of IMPP_xGnP ${ }^{25}{ }_{4} \%$ clearly indicates poor adhesion between the filler and the matrix in the absence of PP-gMA. Thus, the decrease in elongation at break for this neat composite and the comparably larger decrease in elongation at break for similar composites containing coupling agent is explained and justified.

Figure 23 is provided to illustrate the change in microscopic morphology of the tensile fracture surface with increased filler loading. In Fig. 23a, the neat IMPP is seen

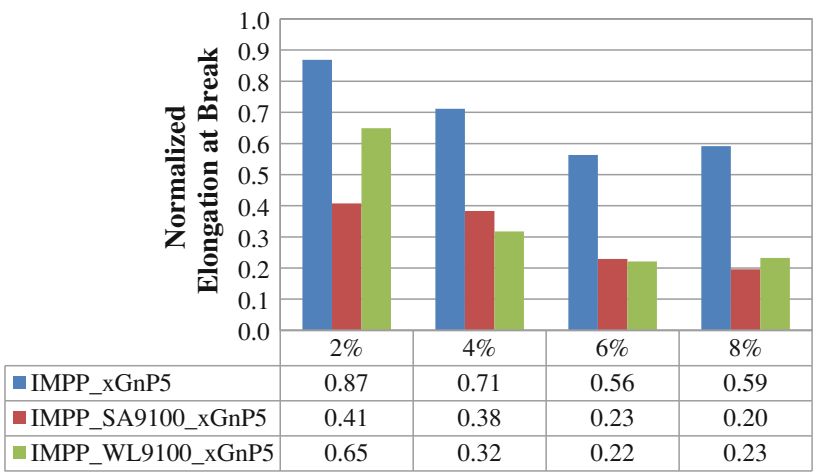

Fig. 19 Normalized elongation at break experimental results for $\mathrm{xGnP} \mathrm{P}^{5}$-filled composites

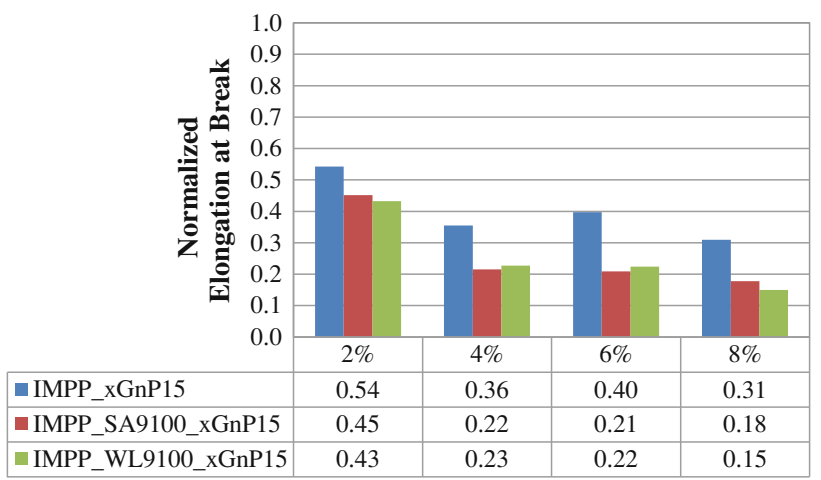

Fig. 20 Normalized elongation at break experimental results for $\mathrm{xGnP}^{15}$-filled composites

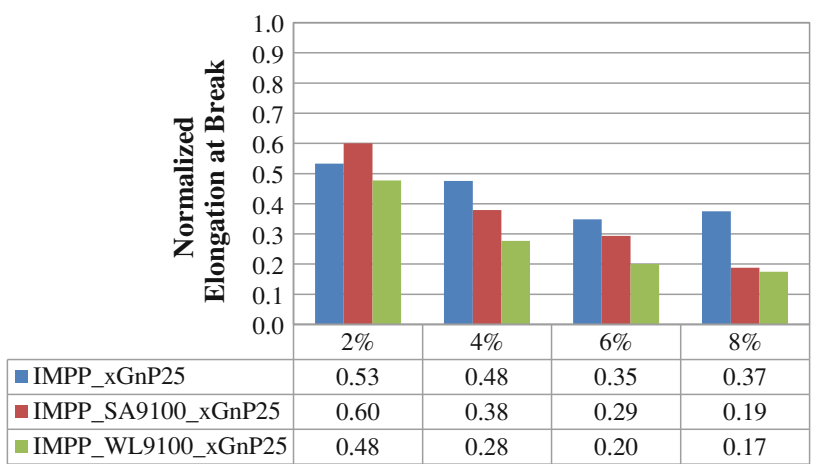

Fig. 21 Normalized elongation at break experimental results for $\mathrm{xGnP}^{25}$-filled composites

to exhibit a fracture surface consisting of many elongated ligaments of polymer, indicating a considerably ductile failure. Figure $23 \mathrm{~b}$ and $\mathrm{c}$ shows neat $\mathrm{xGnP}^{25}$-filled composites at 2 and $4 \%$ filler loading, respectively. At $2 \%$ filler loading, a decrease is seen in the amount of elongated polymer present on the fracture surface as well as a cavity, indicated by the red arrow, where an agglomeration of $\mathrm{xGnP}^{25}$ platelets have pulled-out. At $4 \%$ filler loading, we can see a further decrease in the density of elongated 
Fig. 22 Scanning electron micrographs illustrating poor particle/matrix adhesion in tensile fracture surface of IMPP_xGnP ${ }^{25} 4 \%$ at $\mathbf{a} \times 1,200, \mathbf{b} \times 6,200$, and c $\times 13,000$ magnification
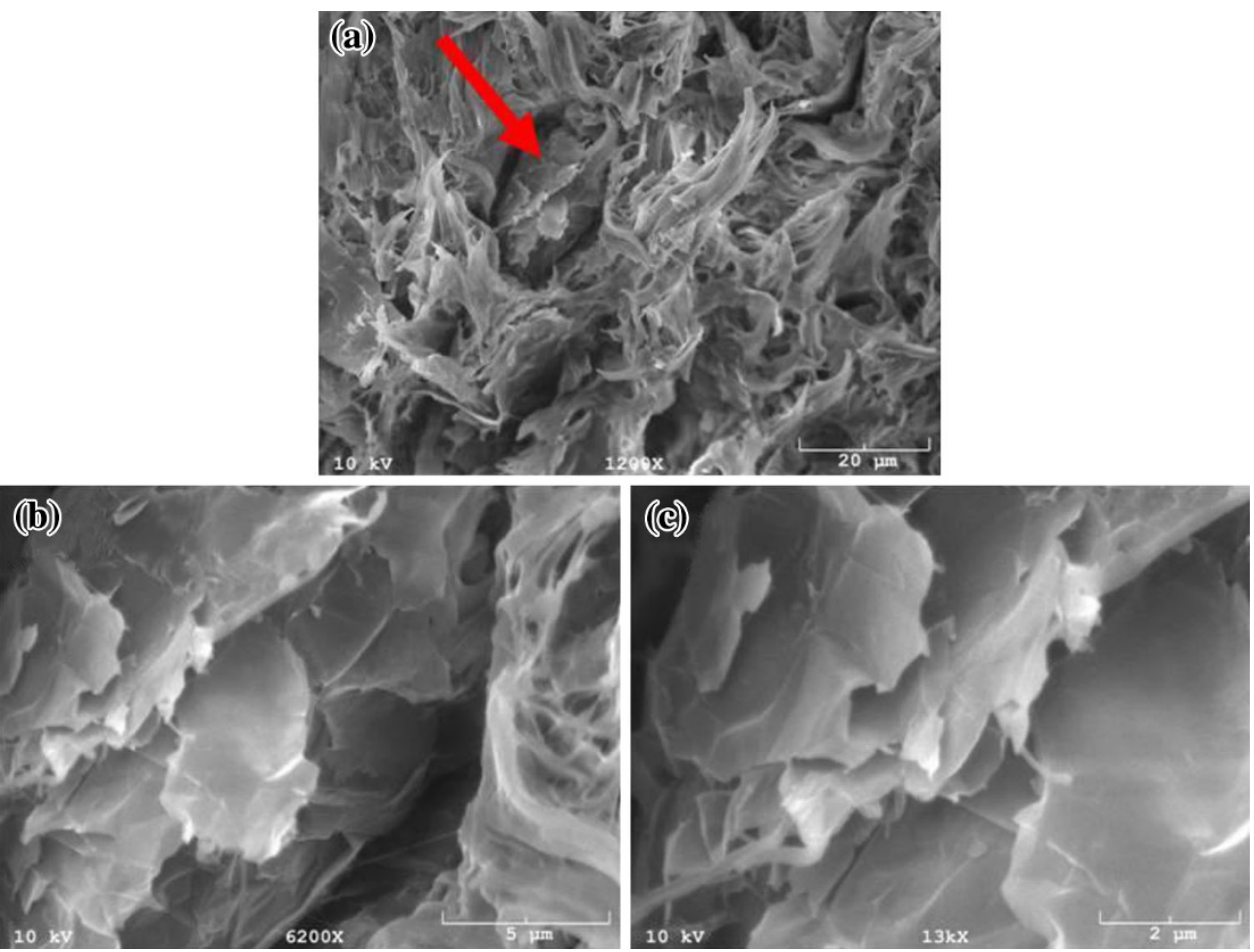

polymer on the fracture surface as well as an agglomeration of $\mathrm{xGnP}^{25}$ platelets, indicated by the red arrow, which again illustrate poor adhesion in the absence of PP-g-MA. Finally, in Fig. 23d at $6 \%$ filler loading, there is essentially no presence of elongated ligaments of polymer. Instead there is very smooth fracture surface, indicative of a considerably brittle failure.

Fig. 23 Scanning electron micrographs illustrating progressively brittle failure surfaces in tensile fracture surfaces of a neat IMPP, b IMPP_xGnP ${ }^{25} \_\%$, c IMPP_xGnP ${ }^{25}-4 \%$, and d IMPP_xGnP ${ }^{25}{ }_{-} 6 \%$
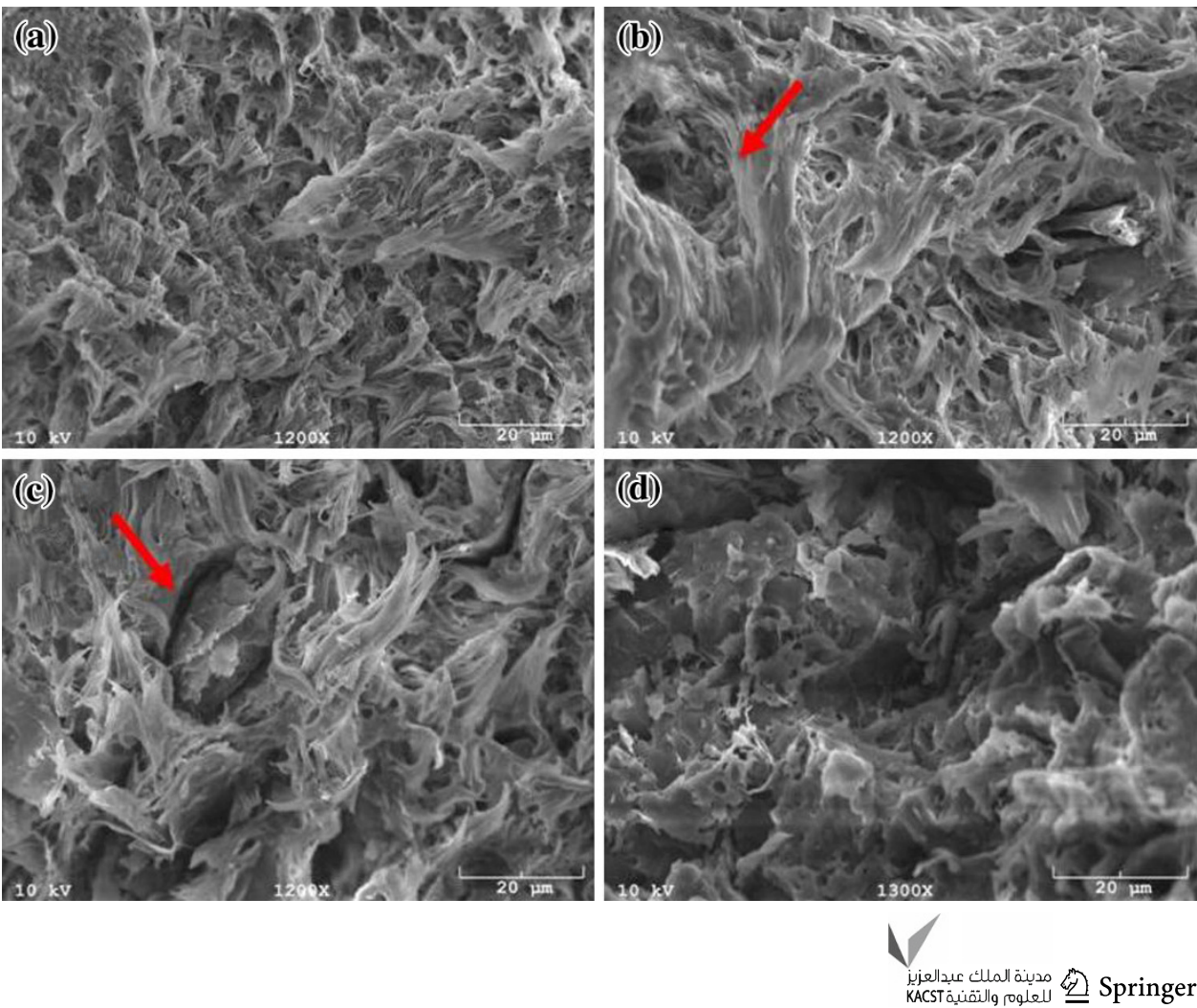
Table 6 Summary of tensile mechanical properties and statistical significance (Tukey-Kramer HSD comparison at $\alpha=0.05$ ) of all compounded materials

\begin{tabular}{|c|c|c|c|c|c|c|}
\hline \multirow{3}{*}{$\begin{array}{l}\text { Study label } \\
\text { Neat IMPP }\end{array}$} & \multicolumn{6}{|c|}{ Tensile properties } \\
\hline & \multicolumn{2}{|c|}{ Elastic modulus (GPa) } & \multicolumn{2}{|c|}{ Strength (MPa) } & \multicolumn{2}{|c|}{ Elongation at break (\%) } \\
\hline & LMNOPQR & $1.29(0.04)$ & HIJKLMNO & $21.3(0.3)$ & $\mathrm{A}$ & $33.8(5.4)$ \\
\hline IMPP_xGnP ${ }^{5} \_2 \%$ & HIJKLMN & $1.38(0.06)$ & $\mathrm{CDE}$ & $22.1(0.3)$ & $\mathrm{AB}$ & $29.4(10.5)$ \\
\hline IMPP_xGnP ${ }^{5} \_4 \%$ & LMNOPQ & $1.32(0.13)$ & EFGHIJ & $21.7(0.3)$ & $\mathrm{BC}$ & $24.0(10.4)$ \\
\hline IMPP_xGnP ${ }^{5} \_6 \%$ & GHIJKL & $1.40(0.05)$ & HIJKLM & $21.5(0.2)$ & CDEFG & $19.0(3.4)$ \\
\hline IMPP_xGnP ${ }^{5} \_8 \%$ & GHIJKL & $1.40(0.04)$ & IJKLMN & $21.3(0.2)$ & $\mathrm{CDE}$ & $20.0(5.8)$ \\
\hline IMPP_SA9100_xGnP 5 _2\% & KLMNOP & $1.33(0.04)$ & DEFGHI & $21.8(0.3)$ & EFGHIJKL & $13.8(4.3)$ \\
\hline IMPP_SA9100_xGnP ${ }^{5} \_\%$ & EFGHI & $1.48(0.04)$ & CDEFGH & $21.9(0.2)$ & FGHIJKLMNO & $12.9(3.2)$ \\
\hline IMPP_SA9100_xGnP $5 \%$ & $\mathrm{CDE}$ & $1.57(0.08)$ & EFGHI & $21.8(0.2)$ & JKLMNOP & $7.8(1.6)$ \\
\hline IMPP_SA9100_xGnP ${ }^{5} \_8 \%$ & $\mathrm{~A}$ & $1.73(0.04)$ & CDEFGH & $21.9(0.3)$ & MNOP & $6.6(1.3)$ \\
\hline IMPP_WL9100_xGnP $52 \%$ & JKLMNOP & $1.37(0.04)$ & $\mathrm{A}$ & $23.9(0.3)$ & $\mathrm{CD}$ & $21.9(5.8)$ \\
\hline IMPP_WL9100_xGnP 5 _4 \% & DEF & $1.52(0.07)$ & $\mathrm{B}$ & $22.7(0.2)$ & IJKLMNOP & $10.7(3.3)$ \\
\hline IMPP_WL9100_xGnP ${ }^{5}$-6\% & $\mathrm{BCDE}$ & $1.59(0.05)$ & $\mathrm{BC}$ & $22.3(0.5)$ & KLMNOP & $7.5(2.0)$ \\
\hline IMPP_WL9100_xGnP $58 \%$ & $\mathrm{AB}$ & $1.68(0.05)$ & $\mathrm{BCD}$ & $22.3(0.3)$ & JKLMNOP & $7.9(1.1)$ \\
\hline IMPP_xGnP ${ }^{15} \_2 \%$ & KLMNOP & $1.36(0.06)$ & LMNOP & $21.0(0.3)$ & CDEF & $18.4(4.4)$ \\
\hline IMPP_xGnP ${ }^{15} \_4 \%$ & GHIJKL & $1.39(0.05)$ & $\mathrm{TU}$ & $20.3(0.3)$ & EFGHIJK & $12.0(4.3)$ \\
\hline IMPP_xGnP ${ }^{15} \_6 \%$ & LMNOPQ & $1.31(0.22)$ & MNOPQ & $21.0(0.3)$ & EFGHIJKLM & $13.4(3.6)$ \\
\hline IMPP_xGnP ${ }^{15} \_8 \%$ & GHIJKLM & $1.39(0.07)$ & $\mathrm{V}$ & $19.4(0.2)$ & HIJKLMNOP & $10.5(1.3)$ \\
\hline IMPP_SA9100_xGnP ${ }^{15} \_2 \%$ & KLMNOP & $1.33(0.03)$ & FGHIJKL & $21.0(0.3)$ & DEFGHI & $15.3(2.9)$ \\
\hline IMPP_SA9100_xGnP ${ }^{15} \_4 \%$ & EFGHIJ & $1.48(0.03)$ & QRST & $20.3(0.3)$ & LMNOP & $7.3(1.3)$ \\
\hline IMPP_SA9100_xGnP ${ }^{15} \_6 \%$ & EFGH & $1.49(0.06)$ & STU & $21.0(0.3)$ & LMNOP & $7.1(1.0)$ \\
\hline IMPP_SA9100_xGnP ${ }^{15} \_8 \%$ & $\mathrm{ABCD}$ & $1.62(0.07)$ & QRST & $19.4(0.2)$ & $\mathrm{OP}$ & $6.0(0.9)$ \\
\hline IMPP_WL9100_xGnP ${ }^{15} \_2 \%$ & KLMNOP & $1.30(0.02)$ & KLMNOP & $21.2(0.3)$ & EFGHIJ & $14.6(3.5)$ \\
\hline IMPP_WL9100_xGnP ${ }^{15} \_4 \%$ & EFG & $1.50(0.04)$ & JKLMNOP & $21.2(0.3)$ & KLMNOP & $7.7(0.9)$ \\
\hline IMPP_WL9100_xGnP ${ }^{15} \_6 \%$ & $\mathrm{DE}$ & $1.56(0.03)$ & OPQR & $20.8(0.3)$ & KLMNOP & $7.6(1.0)$ \\
\hline IMPP_WL9100_xGnP ${ }^{15} \_8 \%$ & $\mathrm{ABC}$ & $1.68(0.09)$ & NOPQ & $20.9(0.3)$ & $\mathrm{P}$ & $5.1(0.4)$ \\
\hline IMPP_xGnP ${ }^{25} \_2 \%$ & MNOPQR & $1.27(0.05)$ & $\mathrm{CDEF}$ & $22.1(0.3)$ & CDEFGH & $18.0(5.1)$ \\
\hline IMPP_xGnP ${ }^{25} \_4 \%$ & LMNOPQR & $1.28(0.06)$ & GHIJKL & $21.5(0.6)$ & DEFGHI & $16.1(3.2)$ \\
\hline IMPP_xGnP ${ }^{25} \_6 \%$ & PQR & $1.25(0.05)$ & RST & $20.4(0.1)$ & HIJKLMNOP & $11.8(1.2)$ \\
\hline IMPP_xGnP $25 \_8 \%$ & QR & $1.21(0.03)$ & UV & $19.8(0.2)$ & GHIJKLMNO & $12.7(2.3)$ \\
\hline IMPP_SA9100_xGnP $25 \_2 \%$ & $\mathrm{R}$ & $1.17(0.03)$ & FGHIJKL & $21.6(0.2)$ & $\mathrm{CDE}$ & $20.3(8.4)$ \\
\hline IMPP_SA9100_xGnP 25 _4\% & OPQR & $1.26(0.04)$ & PQRS & $20.7(0.4)$ & FGHIJKLMNO & $12.8(3.1)$ \\
\hline IMPP_SA9100_xGnP ${ }^{25} \_6 \%$ & LMNOPQ & $1.30(0.04)$ & LMNOP & $21.1(0.3)$ & IJKLMNOP & $9.9(1.5)$ \\
\hline IMPP_SA9100_xGnP ${ }^{25} \_8 \%$ & KLMNOP & $1.34(0.05)$ & PQRS & $20.7(0.5)$ & NOP & $6.4(1.0)$ \\
\hline IMPP_WL9100_xGnP ${ }^{25}{ }^{2} \%$ & KLMNOP & $1.33(0.07)$ & $\mathrm{B}$ & $22.8(0.3)$ & DEFGHI & $16.1(3.2)$ \\
\hline IMPP_WL9100_xGnP 25 _4 \% & IJKLMNO & $1.38(0.02)$ & CDEFG & $22.0(0.2)$ & IJKLMNOP & $9.4(1.9)$ \\
\hline IMPP_WL9100_xGnP 25 _6\% & FGHIJK & $1.44(0.08)$ & EFGHIJK & $21.6(0.2)$ & MNOP & $6.8(0.5)$ \\
\hline IMPP_WL9100_xGnP $25 \_8 \%$ & GHIJKLM & $1.39(0.04)$ & NOPQR & $20.8(0.3)$ & $\mathrm{OP}$ & $5.9(0.6)$ \\
\hline
\end{tabular}

Parenthesis indicates standard deviation

Presence of the same letter indicates no statistical difference

stiff inclusions. These stiff inclusions redirect stress concentrations from the elastomeric impact modification (toughening) phase of the IMPP to the much larger and stiffer effective graphite particles. In addition, these agglomerated stacks provide non ideal transfer of stresses between matrix and filler, therefore resulting in early failure or low values of elongation at break compared to the very tough IMPP. Table 6 shows a summary of tensile mechanical properties and statistical significance of all compounded materials. 


\section{Conclusions}

Both $x G n P$-filled IMPP composites with and without the addition of coupling agent were prepared via melt compounding followed by injection molding. Mechanical and morphological characterization yielded conclusions in understanding the influence of particle diameter, filler loading, and coupling agent, on the flexural and tensile properties of xGnP-filled IMPP composites. The smallest diameter filler investigated in this study $(5 \mu \mathrm{m})$ performed the best in terms of flexural and tensile mechanical properties of $x \mathrm{GnP}$-filled IMPP composites. It is suspected that incorporation of $\mathrm{xGnP}$ with an average particle diameter smaller than $5 \mu \mathrm{m}$ would result in largely increased improvements in flexural and tensile properties. Tensile and flexural moduli and strengths both increased with $\mathrm{xGnP}$ filler loading for compatibilized composites. Elongation at break was greatly deteriorated with as little as 2 wt $\% \mathrm{xGnP}$ with and without coupling agent. The addition of coupling agent has been proven to dramatically enhance dispersion within $\mathrm{xGnP}$-filled IMPP composites. Enhanced dispersion has been proven indirectly via mechanical testing and Halpin-Tsai modeling comparisons as well as directly via TEM imaging. However, the addition of coupling agent amplifies the degradation of elongation at break because of the improved adhesion between the filler and the matrix.

Open Access This article is distributed under the terms of the Creative Commons Attribution License which permits any use, distribution, and reproduction in any medium, provided the original author(s) and the source are credited.

\section{References}

Ahmad SH, Rasid R, Surip SN, Anuar H, Czigany T, Abdul Razak SB (2007) Mechanical and fracture toughness behavior of TPNR nanocomposites. J Compos Mater 41(17):2147-2159

Chen GH, Wu DJ, Weng WG, Yan WL (2001) Preparation of polymer/graphite conducting nanocomposite by intercalation polymerization. J Appl Polym Sci 82:2506-2513

Gopakumar TG, Page DJYS (2004) Polypropylene/graphite nanocomposites by thermo-kinetic mixing. Polym Eng Sci 44(6):1162-1169

Hussain F, Hojjati M, Okamoto M, Gorga RE (2006) Review article: polymer-matrix nanocomposites, processing, manufacturing, and application: an overview. J Compos Mater 40(17):1511-1575

Jiang X, Drzal LT (2010) Multifunctional high density polyethylene nanocomposites produced by incorporation of exfoliated graphite nanoplatelets 1: morphology and mechanical properties. Polym Compos 31(6):1091-1098

JMP Statistical Discovery Software, Version 8 SAS Institute, Inc.: Cary, NC (2008)

Kalaitzidou K, Fukushima H, Drzal LT (2007a) A new compounding method for exfoliated graphite-polypropylene nanocomposites with enhanced flexural properties and lower percolation threshold. Compos Sci Technol 67:2045-2051

Kalaitzidou K, Fukushima H, Drzal LT (2007b) Multifunctional polypropylene composites produced by incorporation of exfoliated graphite nanoplatelets. Carbon 45:1446-1452

Kalaitzidou K, Fukushima H, Miyagawa H, Drzal LT (2007c) Flexural and tensile moduli of polypropylene nanocomposites and comparison of experimental data to Halpin-Tsai and Tandon-Weng models. Polym Eng Sci 47:1796-1803

Kalaitzidou K, Fukushima H, Drzal LT (2007) Mechanical properties and morphological characterization of exfoliated graphite-polypropylene nanocomposites. Composites: Part A 38:1675-1682

Kim S, Drzal LT (2009) High latent heat storage and high thermal conductive phase change materials using exfoliated graphite nanoplatelets. Sol Energy Mater Sol Cells 93:136-142

Kim S, Do I, Drzal LT (2009) Multifunctional xGnP/LLDPE nanocomposites prepared by solution compounding using various screw rotating systems. Macromol Mater Eng 294:196-205

Kim S, Do I, Drzal LT (2010a) Thermal stability and dynamic mechanical behavior of exfoliated graphite nanoplateletsLLDPE nanocomposites. Polym Compos 31(5):755-761

Kim S, Seo J, Drzal LT (2010b) Improvement of electric conductivity of LLDPE based nanocomposite by paraffin coating on exfoliated graphite nanoplatelets. Composites Part A 41:581-587

Kim H, Abdala AA, Macosko CW (2010c) Graphene/polymer nanocomposites. Macromolecules 43(16):6515-6530

Miloaga DG, Hosein HAA, Misra M, Drzal LT (2005) nucleating effect of expanded graphite nanoplatelets on Poly(Hydroxybutyrate). Michigan State University, Composite Materials \& Structures Center

Oksman K, Clemons C (1998) Mechanical properties and morphology of impact modified polypropylene-wood flour composites. J Appl Polym Sci 67:1503-1513

Page DJYS, Gopakumar TG (2006) Properties and crystallization of maleated polypropylene/graphite flake nanocomposites. Polym J 38(9):920-929

Pan Y-X, Yu Z-Z, Ou Y-C, Hu G-H (2000) A new process of fabricating electrically conducting nylon 6/graphite nanocomposites via intercalation polymerization. J Polym Sci Part B: Polym Phys 38(12):1626-1633

Park HM, Kalaitzidou K, Fukushima H, Drzal LT (2007) Exfoliated graphite nanoplatelet $(\mathrm{xGnP}) /$ polypropylene nanocomposites. Michigan State University, Composite Materials \& Structures Center

Ratnayake UN, Haworth B, Hourston DJ (2009) Preparation of polypropylene-clay nanocomposites by the co-intercalation of modified polypropylene and short-chain amide molecules. J Appl Polym Sci 112:320-334

Sherman LM (2004) Chasing nanocomposites. Plastics Technol 50(11):56-61

Spoljaric S, Genovese A, Shank RA (2009) Polypropylene-microcrystalline cellulose composites with enhanced compatibility and properties. Compos A Appl Sci Manuf 40(6-7):791-799

Stankovich S, Dikin DA, Dommett GHB, Kohlhaas KM, Zimney EJ, Stach EA, Piner RD, Nguyen ST, Ruof RS (2006) Graphenebased composite materials. Nature 442:282-286

Teng C-C, Ma C-CM, Huang YW, Yuen SM, Weng C-C, Chen C-H, Su SF (2008) Effect of MWCNT content on rheological and dynamic mechanical properties of multiwalled carbon nanotube/ polypropylene composites. Compos Part A 39:1869-1875

Thostenson ET, Li C, Chou TW (2005) Nanocomposites in context. Compos Sci Technol 65:491-516 